\title{
Value Correlations Of Business Information Competencies In Graduate And Undergraduate Studies
}

Donald Caputo, Ph.D. Robert Morris University, USA

Jessica Schreiner, M.S., Computer Associates Corporation, USA

\begin{abstract}
Previous research studies have noted that university students at both the graduate and undergraduate levels are concerned that they do not have the necessary career skills to make the transition from college student to corporate employee, and equally concerned about which specific skills open the door of corporate opportunity. This research study attempts to find which Business Information Skills are relevant to student concerns and whether the educational community is fulfilling their needs. Additionally, the second phase of the study will compare the correlation of the initial findings in regard to the educational status of the student, either graduate or undergraduate. In other words, does the greater employment diversity and job-oriented promotion-intensive outlook of the graduate student result in a different set of views on needed career skills than the undergraduate student. Initial information was derived from surveys of a discrete selection of the corporate community in southwestern Pennsylvania, which resulted in the matrix of employer desired business skills. Relative information was garnered from graduate and undergraduate student surveys at Robert Morris University, which resulted in an essential student overview of perceived essential business skills. All surveyed students were engaged in one or more of the various Computer Systems programs at the university. Doctoral Information Science programs were not included in the survey. The timeframe of the study, on an ongoing basis, encompasses the period from 2005 to mid-2008.
\end{abstract}

Keywords: Computer business skills, Graduate IT education, Employer-defined skills, IT curriculum

\section{INTRODUCTION}

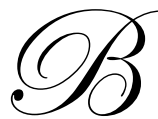

usiness Information Technology has become a vital and growing segment of U.S. economic strength, as well as emerging as one of the key drivers for success in the global economy. Strategic advantage in the business arena can be achieved with the coordinated development of a technology-related workforce that is designed to meet employer-defined needs. The synergy of corporate and academic interests is enhanced when the competencies developed in higher education ensures that the emerging workforce is in sync with the business technology-driven sector. Many diverse categories of business competencies and information technology skills are integrated into the fabric of technological innovation. However, rapid changes, additions and evolution of new methods and standards of business practice needed in the job market now dictates a re-evaluation of these necessary competencies and attributes.

Information Technology (IT) has rapidly become one of the largest segments of the U.S. economy. In western Pennsylvania, the IT cluster (Paytas, 2001) contains more than 1,600 firms that employ more than 39,000 workers, and has accounted for $15 \%$ of the region's job growth over the past decade. This rapid expansion is a challenging and ongoing undertaking for educators in institutions of higher education that prepare Information Technology professionals. In order to meet this challenge, data must be continually collected and analyzed to determine the relevancy and the adequacy of its programs and courses (Modzelewski, 2002). While the universities have the primary responsibility of evaluating each program, Information Technology professionals can provide 
valuable feedback concerning what areas of study and competencies are critical (Smith, 2001). These areas of study and competencies can then be identified as valid entities that must be integrated into the Information Systems programs of colleges and universities.

The first phase of this study relates to, and captures, the expertise of professionals who are involved in the Information Technology field. A survey was conducted from a representation of the western Pennsylvania regional technological corporate community with the following objectives:

1. To identify the areas of study in the Business Information Technologies that are in a process of changing requirements, as assessed by field professionals.

2. To determine which specific categories and competencies are emerging as growth areas requiring increased personnel and corporate resources.

3. To determine which specific categories and competencies are emerging as declining growth areas requiring less personnel and corporate resources.

4. To identify the specific skill areas that are considered to be essential to the business needs of the corporation, and thus, by extension, those qualities that are most highly-prized in the selection of candidates for employment

We continue this phase of the study with an attempt to determine the student perception of the values of the skills available to them through study in the courses of the university. Students completed surveys that listed the same set of competencies and skills that were rated by the corporate IT respondents. The students were asked whether they had already taken courses in specific skill areas, or whether they planned to take the skills during their tenure at the university. Finally, each skill was rated by the student as one that would be considered "essential" to their future job needs. This final response was the criterium that was used as the basis of comparison to the corporate view. Students were not made aware of the ratings of the corporations prior to completing the survey.

The final phase of the research matrix is the comparison of responses by graduate and undergraduate students. The intent is to determine if any significant difference exists in the responses of the discrete groups of students in their perception of business information essential skill values. A series of articles (Tucci, 2007) on "techie" anxiety concerning a lack of relevant business skills highlighted the similar plight of the student experience.

The gathering and evaluation of the data comprised in this study could be of value to the following institutions and individuals.

1. Information Technology departments in colleges and universities as a means of providing reliable information upon which educators can base decisions regarding modifications in curriculum and programs.

2. Information Technology departments in business, industry, and education as an aid in determining standards for the selection and education of their personnel.

3. Students enrolled in Information Technology programs at the graduate and undergraduate level.

4. Individuals employed in Information Technology or students expecting to enter the field within a short time frame who can benefit from an analysis of essential skills with the possibility of being motivated toward self-improvement and preparation for advancement.

\section{ASSUMPTIONS}

This study is predicated upon the following assumptions:

1. Those individuals surveyed are a representative sample of Information Technology practitioners nationally.

2. The Information Technology professionals surveyed are currently using or have used the information skills and business intelligence in their functional role.

3. The individuals surveyed can identify their needs in relation to Areas of Study and Competencies in Information Technology.

4. A survey of Information Technology professionals is crucial to the revision and development of higher education programs if such programs are to service the needs of students and working professionals. 
5. The academic survey was comprised of graduate and undergraduate male and female students that were enrolled in one or more of the courses of study leading to an Information Technology degree at Robert Morris University.

\section{DEFINITION OF TERMS}

For the purpose of this research, the following terms will have the meanings indicated below.

Information Technology: A term synonymous with Business Information Systems, Management Information Systems, Computer Science, Computer Information Systems, and Information Sciences.

Categories or functional areas: A set of interrelated activities performed by Business Information Technology professionals in attainment of the expectations imposed by job requirements.

Competencies: Specific knowledge, skills and abilities needed by Business Information Technology professionals for the effective performance of their respective functional role.

\section{POPULATION}

The total population from which the data was drawn for this study included professionals who are involved with Information Technology in business, industrial, governmental, and service organizations in western Pennsylvania. This includes over 1600 corporations within the Pittsburgh Technology Council (PTC) and the Association for Information Technology Professionals (AITP). The geographic area of this population included the city of Pittsburgh and Allegheny County as well as surrounding western Pennsylvania counties including Washington, Butler, Beaver, and Westmoreland. This population is expected to provide sample statistics that would have some meaningful relevance for IT professionals and organizations in other urban areas in the United States (Mitchell, 2006). The sample of the student portion of the survey, as previously noted, consisted of 324 RMU Computer Information System majors. This is a majority of the population.

\section{DATA COLLECTION AND RESEARCH SAMPLE}

In order to meet the objectives of this study, it was necessary to collect, analyze, and summarize empirical data. The questionnaire is described in the following tract.

The questionnaire designed in three main parts was utilized to meet the study objectives. Part I consisted of a Personal and Corporate Profile designed to collect data about the background, experience, corporate hierarchical level, IT service, degrees attained and current professional status of the respondents. Part II consisted of a Program Profile and included questions concerning curriculum. Part III involved a Competency Profile developed to elicit information concerning the expected growth or decline of competency categories and specific skills associated with Information Technology. The study period was concentrated in 2005 and 2006. Whenever possible, follow-up calls or on-site visits were made to enhance the validity and response of the instrument. Of the total questionnaires mailed or given on-site, 127 were completed and returned. These data became the basis for the analysis of data and are referred to as the sample for this study. The number of corporations surveyed in this sample was 101. In a few cases, those corporations having large and diverse IT departments with multiple supervisors and managers in various departments or divisions provided more than one response per corporate entity. Each respondent rated the IT categories and competencies as essential areas in a positive growth curve, or in a negative growth curve. A current and short-term horizon view was taken for the growth pattern (Ware, 2002).

Three categories of corporate dimension were employed for the study. Dimension 1 corporations were those with less than 100 employees. Dimension 2 corporations maintained between 100 and 999 employees. They were generally rapidly growing entities that often maintained multiple sites in the local area. Dimension 3 corporations represented those firms that were often multi-national, multi-divisional and multi-sited in nature. They range in employee force from 1,000 to 142,000 . This broad range of corporate samples ensured that the data was derived from as many sources as possible. 
The broad competency categories that were studied are:

1. Network Administration

2. Windows Development

3. Web Development

4. Database Systems

5. Systems Development

6. Office Software

7. MultiMedia/Graphics

8. Miscellaneous Competencies

Within most of the categories, multiple skills were represented. As an example, under the area of study category for Windows Development, many programming languages were listed (such as C++, Java, Visual Basic, and other current software). Each specific skill was rated for all categories except outsourcing, where the respondents preferred to answer in terms of the broad category, rather than each individual skill. By numbers, 31 specific competencies were examined.

Each of the eight categories and skills (with a single exception) in the areas of study relate directly to courses offered within the curriculum of the Information Technology and Computer Information and Systems department of this university, and many other universities. It is not intended to be all-inclusive. The exception was the last category, Business Intelligence. Previous small-scale surveys conducted by this university indicated that corporate Information Technology managers recognized a potential area of study that would be of major value to their corporations. This category was suggested as an addition to the original list by a majority of the corporate community participants, and thus is included in the survey. It is an elusive skill to categorize, and perhaps not easily meshed into the curricular offerings of the modern higher education system. It is not a single-entity skill, but rather a fusion or combination of assets, insights, capabilities and processes adaptable to the Information Technology discipline. For clarity and standardization purposes, the definition proposed to the Business Information Technology community by this researcher is that "Business/Information Intelligence is the ability to fuse corporate business goals and objectives with relevant and powerful technological processes." The course is now taught by the university under the title "Competitive/Business Intelligence", but wasn't in the curriculum at the time of the corporate study. By any measure, it is regarded as a coveted, highly desirable asset for any IT employee to possess (Smith et al., 2001).

\section{FINDINGS}

Table 1

Skill is Considered Essential When Ranked by More Than 50\% of Corporations as Such

\begin{tabular}{|c|c|c|c|}
\hline Competency Category & Competency Skill & $\begin{array}{l}\text { Corporate Percent } \\
\text { Growth/2005-2008 }\end{array}$ & $\begin{array}{l}\text { Essential Skill } \\
\text { Ranking 2007 }\end{array}$ \\
\hline Network Administration & Network Security & $78 \%$ & $76 \%$ \\
\hline “ & Network Hubs, Routers & $61 \%$ & $46 \%$ \\
\hline “ & Client/Server & $32 \%$ & $50 \%$ \\
\hline " & Telecommunications & $20 \%$ & $47 \%$ \\
\hline “ & Wireless Technology & $38 \%$ & $22 \%$ \\
\hline “ & Cisco & $41 \%$ & $28 \%$ \\
\hline Windows Development & Java & $52 \%$ & $48 \%$ \\
\hline “ & Visual Basic & $52 \%$ & $46 \%$ \\
\hline “ & .NET & $38 \%$ & $53 \%$ \\
\hline “ & $\mathrm{CH}$ & $35 \%$ & $38 \%$ \\
\hline “" & $\mathrm{C} / \mathrm{C}++$ & $38 \%$ & $46 \%$ \\
\hline Web Development & HTML/XML & $41 \%$ & $48 \%$ \\
\hline “" & Javascript & $41 \%$ & $27 \%$ \\
\hline “ & PERL & $14 \%$ & $5 \%$ \\
\hline “" & ASP & $30 \%$ & 18 \\
\hline
\end{tabular}


Table 1 continued

\begin{tabular}{|c|c|c|c|}
\hline Competency Category & Competency Skill & $\begin{array}{l}\text { Corporate Percent } \\
\text { Growth/2005-2008 }\end{array}$ & $\begin{array}{l}\text { Essential Skill } \\
\text { Ranking } 2007\end{array}$ \\
\hline Systems Development & Systems Analysis & $19 \%$ & $42 \%$ \\
\hline 66 & Modeling Tools & $11 \%$ & $29 \%$ \\
\hline “" & Case Tools & $11 \%$ & $29 \%$ \\
\hline Office Software & Database & $49 \%$ & $89 \%$ \\
\hline 6 & Word Processing & $48 \%$ & $89 \%$ \\
\hline 6 & Spreadsheet & $48 \%$ & $89 \%$ \\
\hline MultiMedia/Graphics & Flash & $12 \%$ & $25 \%$ \\
\hline 66 & Adobe Photoshop & $12 \%$ & $17 \%$ \\
\hline Database Systems & $\mathrm{SQL}$ & $70 \%$ & $51 \%$ \\
\hline “ & SQL Server & $43 \%$ & $39 \%$ \\
\hline “6 & DB2 & $22 \%$ & $20 \%$ \\
\hline 66 & Oracle & $78 \%$ & $55 \%$ \\
\hline "“ & Data Mining & $70 \%$ & $35 \%$ \\
\hline Software Development & COBOL: & $14 \%$ & $8 \%$ \\
\hline Project Management & Project Manager & $65 \%$ & $66 \%$ \\
\hline Unix & Linux & $44 \%$ & $31 \%$ \\
\hline Object-Oriented Skills & Gen'1 Programming & $47 \%$ & $27 \%$ \\
\hline Integration Technology & Competitive Intelligence & $81 \%$ & $91 \%$ \\
\hline
\end{tabular}

Table 2

Skill is Perceived as Essential When Ranked by 50\% (=/>) of Students in Each Category

Competency Skill

Network Security

Network Hubs/Routers

Client Server

Telecommunications

Wireless Technology

Cisco

Java

Visual Basic

NET

$\mathrm{C} \#$

$\mathrm{C} / \mathrm{C}++$

HTML/XML

Javascript

PERL

ASP

Systems Analysis

Modeling Tools

Case Tools

MS Office

Flash

Adobe Photoshop

SQL

SQL Server

DB2

Oracle

Data Mining

COBOL

Project Management

Linux

Gen'l Programming

Competitive/Business Intell.
Undergraduate Student Ranking

Graduate Student Ranking

$\begin{array}{rr}76 \% & 54 \% \\ 39 \% & 39 \% \\ 48 \% & 33 \% \\ 36 \% & 32 \% \\ 48 \% & 42 \% \\ 27 \% & 23 \% \\ 32 \% & 23 \% \\ 34 \% & 31 \% \\ 42 \% & 50 \% \\ 15 \% & 15 \% \\ 29 \% & 19 \% \\ 35 \% & 28 \% \\ 26 \% & 24 \% \\ 8 \% & 7 \% \\ 22 \% & 20 \% \\ 43 \% & 39 \% \\ 27 \% & 20 \% \\ 34 \% & 29 \% \\ 67 \% & 57 \% \\ 17 \% & 8 \% \\ 11 \% & 9 \% \\ 52 \% & 40 \% \\ 54 \% & 44 \% \\ 15 \% & 22 \% \\ 50 \% & 40 \% \\ 22 \% & 28 \% \\ 8 \% & 5 \% \\ 47 \% & 57 \% \\ 37 \% & 22 \% \\ 38 \% & 33 \% \\ 43 \% & 50 \% \\ & \\ & \end{array}$


Table 3

Correlation between Student Perceptions and Corporate Projections

\begin{tabular}{lcc}
\hline & Undergraduate & Graduate \\
\hline Network Security & & + \\
NET & & + \\
MS Office & + & + \\
SQL & + & \\
SQL Server & + & \\
Oracle & + & + \\
Project Management & & +
\end{tabular}

The positive (+) correlations indicate that the students in each category correctly perceived these skills as essential consistent with the ranking generated by the corporate IT community. The areas not ranked were those that fell below the 50\% threshold in either student or corporate rankings, and thus were not included in the matrix.

The percentage of variance for each of the 31 categories of business information skills deviated by an average of only 6.2 percent, thus indicating that graduate and undergraduate students perceived only minimal differences

in the ranking matrix.

\section{SUMMARY AND RECOMMENDATIONS}

The corporate percent growth/decline column indicates the percentage of companies that evaluated each specific competency as a growth area in terms of allocated resources and personnel acquisition.

Business Information Technology management timed their assessments to current and future short-term needs.

Categories of competencies relate directly to areas of study within the curriculum of most institutions of higher education. The only exception is the Business Intelligence category. The high positive responses elicited from corporate management personnel for this subject indicates that it would be a welcome addition to the structure of Business Information Processing educational offerings. As previously noted, it is now in the university curriculum.

It is important to note that the motivation for this study was the often-expressed concern of the student that he/she did not have the necessary skills to commence a career in the Information Technology field or that the acquired skills were not the ones that are of current interest to the corporate world. This is a very common reaction throughout the nation's academic institutions, and can be verified by many studies (Tucci, 2007).

\section{AUTHOR INFORMATION}

Dr. Donald Caputo is a Computer and Information Systems Professor at Robert Morris University. He previously taught at Penn State University as an Engineering and Computer Science Assistant Professor, specializing in Computer Languages. Additionally, he was an Adjunct Professor in the Doctoral Program in Information and Library Sciences at the University of Pittsburgh.

Dr. Caputo received his Ph.D. in Educational Technology Information Systems at the University of Pittsburgh.

His corporate career began with U.S. Steel Corporation as a Systems Analyst for Corporate Business Systems, continuing as an Information Business Analyst with PPG Corporation.

Dr. Caputo has published in numerous professional Journals associated with IACIS, ISECON, IBER, NEDSI and M Computing.

Jessica Schreiner: M.S., M.B.A., Robert Morris University, Information Business Analyst, Computer Associates Corporation. 


\section{REFERENCES}

1. Modzelewski, Eve (2002). Tech Jobs Go Begging for Lack of Workers in Area, Pittsburgh Post-Gazette, June 27, 2002.

2. Mitchell, Robert and Bailey, Janet (2006). Industry Perceptions of the Competencies Needed By Computer Programmers: Technical, Business, and Soft Skills, Journal of Computer and Information Systems, Winter 2006-2007.

3. Paytas, Jerry (2001). Southwestern Pennsylvania Industry Executive Summary, Southwestern Pennsylvania Industrial Cluster Analysis, Pittsburgh Technology Council, Pittsburgh, PA, December, 2001.

4. Smith, Donald F., et al, (2001). The Educational Needs. Southwestern Pennsylvania Industry Cluster Analysis, Pittsburgh Technology Council, Pittsburgh, PA, December, 2001.

5. Tucci, Linda (2007). Techies Anxious about Lack of Business Skills, Global Knowledge IT Training, May 2007.

6. Ware, Lorraine (2002). Southwestern Pennsylvania Industry Executive Summary, Southwestern Pennsylvania Industrial Cluster Analysis, Pittsburgh Technology Council, Pittsburgh, PA, December, 2001. 
NOTES 